\title{
Bayesian model-based approach for developing a river water quality index
}

\begin{abstract}
Six main pollutants have been previously identified by expert opinion to determine river condition in Malaysia. The pollutants were Dissolved Oxygen (DO), Biochemical Oxygen Demand (BOD), Chemical Oxygen Demand (COD), Suspended Solid (SS), potential of Hydrogen $(\mathrm{pH})$ and Ammonia $(\mathrm{AN})$. The selected variables together with the respective weights have been applied to calculate the water quality index of all rivers in Malaysia. However, the relative weights established in DOE-WQI formula are subjective in nature and not unanimously agreed upon, as indicated by different weight being proposed for the same variables by various panels of experts. Focusing on the Langat River, a Bayesian modelbased approach was introduced for the first time in this study to obtain new objective relative weights. The new weights used in WQI calculation are shown to be capable of capturing similar distributions in water quality compared with the existing DOE-WQI.
\end{abstract}

Keyword: Bayesian model-based approach; Water quality; Bayesian analysis; Langat River 